\title{
Study on Task-based Language Teaching
}

\author{
Lidan $\mathrm{Yu}$ \\ School of Foreign Language \\ Huanghe Science and Technology College \\ Zhengzhou, China 450005
}

\begin{abstract}
Task-based Language Teaching is an approach to the design of language course in which the point of departure is not an ordered list of linguistic items, but a collection of tasks. From the above definition, we can see that the purpose of TBLT is to make the learners learn some relevant language by implementing tasks.
\end{abstract}

Keywords—Language Teaching; language course; Task

\section{REVIEW OF TASK}

\section{A. Definitions of Task}

What is task? Different linguists and researchers have given different definitions from different perspectives. Here are several representative definitions of task:

The most general definition used by Long (1985:89) is that: (Task is) a piece of work undertaken for oneself or for others, freely or for some reward. Thus, examples of task including painting a fence, dressing a child, filling out a form, buying a pair of shoes, making an airline reservation, borrowing a library book, taking a driving test, typing a letter, weighing a patient, sorting letters, taking a hotel reservation, writing a check, finding a street destination and helping someone across a road. In other words, by "task" is meant the hundred and one things people do in everyday life, at work, at play, and in between.

Breen (1987:23) explains the instructional roles of a task, a range of work plans which have the overall purpose of facilitating language learning-from the simple and brief exercise type, to more complex and lengthy activities such as group problem-solving or simulations and decision-making.

Nunan (1989:10) thinks that task is a piece of classroom work which involves learners in comprehending, manipulating, producing or interacting in the target language while their attention is principally focused on meaning rather than form. The task should also have a sense of completeness, being able to stand alone as a communicative act in its own right with a beginning, middle and an end. This definition was given from the communicative perspective, focusing on meaning rather than on form.

Begate, Skehan \& Swain (2001:11) offer a definition: A task is an activity influenced by learner choice and susceptible to learner reinterpretation, which requires learners to use language, with emphasis on meaning to achieve an objective.
From all the above definitions, we can draw a conclusion that a task is a meaningful activity. The aim of a task is to combine language study and language use naturally in real life. The task involves the actual use of language. The task requires learners to solve communication problems by using language. Tasks provide the teachers and students with authentic language information and help learners to learn and use language. The results of the task are the feedback to the implementation and completion of tasks.

\section{B. Components of Task}

In order to design tasks which are suitable for EFL students, it is important to clarify the components of tasks. Candlin (1987) suggests that tasks should contain input, roles, settings, actions, monitoring, outcomes and feedback. Input refers to the data presented for learners to work on. Roles specify the relationship between participants in a task. Settings refer to the classroom and out of class arrangements entailed in the task. Actions are the procedures and sub-tasks to be performed by learners. Monitoring refers to the supervision of the task in progress. Outcomes are the goals of the task and feedback refers to the evaluation of the task.

According to Nunan (1989:48), tasks should contain six parts: goals, input, activities, teacher's role, student's role and settings.

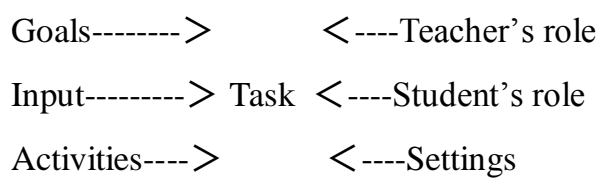

Nunan (1989:48-49) explains these components as follows:

Goals are the vague general intentions behind any given learning task. They provide a link between the task and the broader curriculum. Goals may relate to a range of general outcomes (communicative, affective or cognitive) or may directly describe teacher or learner's behavior.

Input refers to data that form the point of the departure for the task. In fact, input for communicative tasks can be derived from a wide range of source.

Activities refer to the performance of a task itself on the basis of goals and inputs. Nunan (1989) proposes three general ways of characterizing activities:

- rehearsal for the real world (authenticity); 
- $\quad$ skills use;

- fluency and accuracy.

Teacher's role means that a teacher is a facilitator, an organizer, a monitor, sometimes a partner of the students while student's role means that students are communicators or conversational partners.

Settings refer to the classroom arrangements and classroom organizing forms specified or implied in a task, e.g. pair work, group work and so on, and also require consideration of whether the task is to be carried wholly or partly outside the classroom.

From all of those, we can draw a conclusion: all of the six components should serve for the core of tasks and all of them provided a skeleton for designing tasks.

\section{Types of Task}

Different researchers classified the types of tasks in different ways, in the following, there are two representative types of tasks.

In Banglore Project (Prabhu, 1987:46-47), Prabhu distinguishes three general types of tasks based on the kind of cognitive activity:

- Information-gap activity, which involves a transfer of given information from one person to another, or from one form to another, or from one place to another, generally calling for the encoding or decoding of information from or into language as well, and learners may have to meet criteria of completeness and correctness in making the transfer.

- Reasoning-gap activity, which involves deriving some new information from given information through process of inference, deduction, practical reasoning, or a perception of relationship or patterns.

- Opinion-gap activity, which involves identifying and articulating a person preference, feeling, or attitude in response to a given situation.

Breen (1985:66) says "task in the classroom should generate authentic language learning behavior which would involve communication and meta-communication during and about the learning." That includes two kinds of task: language learning task and communication task.

From the above findings, we can conclude that tasks including information-gap activity, reasoning-gap activity and opinion-gap activity, thus teachers should consider which type of tasks should be given to the students before assigning tasks to students. Also teachers should pay more attention to authentic tasks in task designing.

\section{Features of Task}

Features of tasks provide teachers the bases of teaching in language teaching process. Skehan (1998:95) provides five features of a task:

- meaning is primary;
- there is some communicative problem to solve;

- there is some sort of relationship to comparable realworld activities;

- task completion has some priority;

- the assessment of task is in terms of outcome.

According to Professor Lu Ziwen $(2002,6)$, there are five features of a task:

- It is a new form of the communicative approach rather than a substitute;

- It focuses on the teaching process, with an attempt to make the student involved in the learning process by completing real life tasks;

- It focuses on the development of the ability on the part of the students to use English for communication;

- It focuses on the use of real life tasks as the central teaching activity;

- It requires that the teaching activities should contribute to the development of the students' comprehensive language use ability.

According to the two scholars who gave the features to task, we can draw a conclusion that we should pay attention to solving problems in tasks through language and focused on meaning instead of language form and structure.

\section{REVIEW OF TBLT}

\section{A. Definition of TBLT}

Nunan (2004:24) defines Task-based Language Teaching as follows: "Task-Based Language Teaching is an approach to the design of language course in which the point of departure is not an ordered list of linguistic items, but a collection of tasks." From the above definition, we can see that the purpose of TBLT is to make the learners learn some relevant language by implementing tasks.

\section{B. Features of TBLT}

Different scholars gave different features to TBLT, here are the main features of TBLT

Nunan (1991:279) provides the following five features of TBLT:

- An emphasis on learning to communicate through interaction in the target language.

- The introduction of authentic texts into the learning situation.

- The provision of opportunities for learners to focus, not only on language, but also on the learning process itself.

- An enhancement of the learners' own personal experiences as important contributing elements to classroom learning. 
- An attempt to link classroom language learning with language activation outside the classroom.

Feez (1998:17) provides six features of TBLT:

- The focus is on the process rather than product.

- Basic elements are purposeful activities and tasks that emphasize communication and meaning.

- Learners learn language by interacting communicatively and purposefully while engaged in the activities and tasks.

- Activities can be either: those that learners might need to achieve in real life or those that have a pedagogical purpose specific to the classroom.

- Activities and tasks of a task-based syllabus are sequenced according to difficulty.

- The difficulty of a task depends on a range of factors including the previous experience of the learner, the complexity of the task, the language required to undertake the task, and the degree of support available.

According to Breen (1987), we may sum up the features of TBLT in the following ways:

From what knowledge the TBLT focuses on, we can see it focuses on communicative knowledge as a unity of text, interpersonal behavior, and identification; the learner's experience and awareness of working upon a new language.

From what capabilities the TBLT focus on and prioritize, we can see it focuses on and prioritize the communicative abilities, learning capability and the ability to negotiate meaning; the ability to interpret meaning and the ability to express meaning.

From what basis the TBLT selects and subdivides what is to be learned, we can see it bases on three aspects: communication tasks, learning tasks, and subdivision.

From how the TBLT sequences what is to be learned, we may find that sequencing can be characterized as cyclic in relation to how learners move through tasks, and as problembased in relation to the on-going difficulties which learners themselves discover.

\section{Model of TBLT}

Many researchers have given different models to TBLT, the most famous and widely used is the model put forward by Jane Willis. In the following part, the author will give a review of it.

Jane Willis made great contributions to TBLT. In her book, A Framework for Task-based Learning (1996), she suggests that the task based on learning activities should emphasize meaning and usage in language learning.

Willis' task-implementing model has been adopted by many teachers when implementing the TBLT model in class. The author of this thesis will take Willis' model.
- Pre-task :Introduction to topic and task

- Task Cycle: Task $\rightarrow$ Planning $\rightarrow$ Report

- Language Focus: Analysis and Practice

From above information, we can see that this model has been divided into three stages: pre-task, task cycle and language focus.

1) Pre-task phase: Teachers may introduce some topicrelated words and phrases to stimulate students' motivation and enthusiasm. Then teachers highlight some related words, phrases and sentences, ask students to do some preparations for understanding the topic-based task. For example, teachers ask students to use dictionaries or internet, brainstorming ideas with classmates, or use personal experience to introduce the topic.

2) Task-Cycle phase

a) Task: In this stage, teachers ask students to do the task in pairs or groups. Let students express their ideas freely by using the language they have already learned. Teachers will play the role of monitors, not correcting the mistakes that students made. Teachers may help students when they need help.

b) Planning: In this stage, students were asked to report how they implemented the tasks and what the results were. Teachers play the role of helpers. Teachers go around the class, give language advice to students, and correct their language mistakes.

c) Report: Teachers ask some pairs or groups to report to the whole class briefly so everyone can compare findings. Teachers play the role of chairpersons. Teachers chair the class and make comments on students' report.

\section{3) Language Focus phase}

a) Analysis: The aim of analysis activities is to encourage learners to investigate language for themselves, and to form and test their own hypotheses about how language works (Willis, 1996:102).Teachers may help students to explore new words, phrases and sentences. Students look for specific features of the text or transcript. Teachers help students to develop an awareness of aspects of syntax, collocation and lexis during the analysis.

b) Practice: Teachers ask students to make some sentences with new words, phrases and sentences based on the language analysis work, or using examples from the text or transcript. Tasks based on texts and transcripts provide students with an exposure to spoken and written language. This provides students with a natural acquisition environment.

\section{Principles of TBLT}

Task-Based Language Teaching should follow some principles, so the teachers know how to implement tasks effectively, and how the students are guided to work on the tasks, the following researchers gave their own opinions on TBLT principles. Willis (1996) proposes five principles for TBLT: 
- There should be exposure to worthwhile and authentic language.

- There should be use of language.

- Tasks should motivate learners to engage in language use.

- There should be a focus on language at some points in a task cycle.

- The focus on language should be more or less important at different times.

Nunan (2004) offers eight principles of TBLT in his book Task-Based Language Teaching.

- Scaffolding principle: Lessons and materials should provide supporting frameworks within which the learning takes place. At the beginning of the learning process, learners should not be expected to produce language that has not been introduced either explicitly or implicitly.

- Task dependency principle: Within a lesson, one task should grow out of, and build upon, the ones that have gone before.

- Recycling principle: Recycling language maximizes opportunities for learning and activates the "organic" learning principle.

- Active learning principle: Learners learn best by actively using the language they are learning.

- Integration principle: Learners should be taught in ways that make clear the relationships between grammatical form, ommunicative function and semantic meaning.

- Reproduction to creation principle: In reproductive tasks, learners reproduce language models provided by the teacher, the textbook or the tape. These tasks are designed to give learners mastery of form, meaning and function, and provide a basis for creative tasks. In creative tasks, learners are recombining familiar elements in novel ways.

- Reflection principle: Learners should be given opportunities to reflect on what they have learned and how well they are doing.

- Learning by doing principle: Learning by doing motivates students to fulfill their potential. Learners master the language by using it communicatively in the classroom, although they still have to learn grammar and memorize vocabularies.

The author of this thesis will take Nunan's eight principles. Principles are abstract, teachers should pay attention to whether or not techniques are effective in promoting learning objectives. Tasks should be designed according to principles in the authentic activities to realize the goal of teaching.

\section{THEORETICAL FOUNDATIONS OF TBLT}

In order to implement TBLT effectively, we should pay attention to the theoretical bases. There are many theoretical bases of TBLT, the present study focuses on the following three bases. The theoretical foundations of TBLT are the Input Hypothesis, the Interaction Hypothesis and the Constructivism Hypothesis.

\section{A. The Input Hypothesis}

The input hypothesis is an important hypothesis of Krashen's theories of second language acquisition. Krashen tries to use this hypothesis to explain how learners acquire a second language. Krashen (1985:2) holds that "human acquire language along the natural order by understanding input that contains structures a bit beyond their current level of competence, they move from i, their current level, to i+1, the next level along the natural order, by understanding input i+1. So the learner cannot master language without essential comprehensible input. When that input surpassed the learner's current language level, acquisition naturally occurred." Comprehension may be at the heart of the language acquisition process. We acquire knowledge by understanding language that is "a little beyond" our current level of competence. This is done with the aid of extralinguistic context or our knowledge of the world. In more formal terms, if an acquirer is at stage " $\mathrm{i}$ " in acquisition of syntax, he or she can progress to stage " $\mathrm{i}+1$ " by understanding input at that level of complexity.

Input, including teaching materials, teacher's talk, learners' talk, plays a significant role in a second language classroom. Cook (1991: 98) states: "Where the purpose of language teaching in a sense is to provide optimal samples of language for the learner to profit from the best input to the process of language learning." The teacher should be careful about the input in the classroom and make sure that the input has a good effect on learners' learning, as Cook (1991: 99) suggests: "The teacher's responsibility is to make certain that the language input that is provided is sufficient for the students to gain the appropriate type of language knowledge and does not distort it in crucial ways."

In TBLT, the designing and performance of tasks provide chances of input to students. The designing task stage should suit to students' different language competence to make the communication more effectively.

\section{B. The Interaction Hypothesis}

The Interaction Hypothesis, which was first advanced by Michael Long in the early 1980s, is put forward as a further supplement or extension of the Input Hypothesis in the field of second language acquisition. In his hypothesis, Long argues that greater attention should be paid to the interaction in which learners are engaged, in order to understand more fully the nature and usefulness of input for second language acquisition. These interactions should not be seen simply as a one-directional source of target language input, feeding into the learner's presumed internal acquisition device. In fact, the more the input is queried, recycled and paraphrased, the greater its potential usefulness as input (Mitchell \& Myles, 
2004:160). Long places emphasis on the importance of the interaction modifications applied by both participants of the interaction, which he thinks promote the comprehension as well as the communication process. In addition, in his point of view, interaction input is more important than noninteractive input (Ellis, 1994:273).

To sum up, Long's Interaction Hypothesis emphasizes the importance of comprehensible input but claims that it is most effective when it is modified through the negotiation of meanings. The characteristic of TBLT is multi-level interaction, learners learn the language through participation in purposeful interactive activities. When implementing interactive tasks, learners solve problems in a cooperative or collaborative way. In the problem-solving process, learners must receive, process, and transmit information. During this process, learners may experience difficulties in understanding or expression. In order to solve these problems, learners must adjust their output which based on the feedback provided by each part, and then ensure the smooth exchange of information. All of these prove that interaction is conducive to language learning.

\section{The Constructivism Hypothesis}

Constructivism emphasizes that learners do not transfer knowledge from the external world into their memories; rather, they create interpretations of the world based upon their past experiences and their interactions in the world. How someone construes the world, their existing metaphors, is at least as powerful a factor influencing what is learned as any characteristic of that world (Cunningham, 1992:36). While Constructivism does not necessarily deny the existence of an objective reality, it does deny the existence of an objective knowledge since "there are many ways to structure the world, and there are many meanings or perspectives for any event or concept"(Duffy \& Jonassen, 1992).

According to constructivism theory, learning and development are social and cooperative activities. Such activities can not be taught, knowledge is constructed by learners themselves, not passed by others. Students may discover and have perception of their living environment through various activities, such as listening, speaking, reading and writing, then construct their own unique understanding. Constructivism has been reflected in TBLT. TBLT provides valuable knowledge experiencing process, it advocates authentic and natural teaching tasks. Through implementation of tasks, learners participate in activities to promote their own reconstruction of knowledge, and promote the integration between new information and learners' existing knowledge.

Once learners experience meaningful participation in activities and feel the success of constructing new knowledge, they will be more active in learning. All of these accelerate the internalization of language information, which is the pursuit of TBLT.

\section{REFERENCES}

[1] Bygate, M.P., Skehan, P. and Swain, M. Researching Pedagogic Tasks: Second Language Learning, Teaching \&Testing. Oxford:Oxford University Press, 2001.

[2] Candlin, C. 'Towards Task-based Learning.'In Candlin, C \& Murphy, D. (Eds.) Language Learning Tasks . Englewood Cliffs, New York:Prentice Hall, 1987

[3] Celce-Murcia, M. Discourse analysis and the teaching of listening. In Cook, G. \& Seidlhofer (eds), B. Principles and Practice in Applied Linguistics. Oxford: Oxford University Press, 1995: 363-377.

[4] Cook, V. Second Language Learning and Language Teaching. London: Edward Arnold. 1991.

[5] Cook, V. Second Language Learning and Language Teaching. Beijing: Foreign Language Teaching and Research Press, 2000.

[6] Cunningham, D. J. Assessing Constructions and Constructing Assessments: A Dialogue. In Duffy \& Jonassen (Eds.), Constructivism and the Technology of Instruction: A Conversation (36-43). Hillsdale, NJ: Lawrence Erlbaum Associates, Inc, 1992.

[7] Davies, P. \& Pearse, E. Success in English Teaching. Shanghai: Shanghai Foreign Language Educational Press, 2002.

[8] Duffy, T. M. and Jonassen, D. H. (Eds.). Constructivism and the Technology of Instruction: A conversation. Hillsdale NJ: Erlbaum. 1992.

[9] Ellis, R. The Study of Second Language Acquisition. Oxford:Oxford University Press, 1994.

[10] Ellis, R. Second Language Acquisition. Oxford:Oxford University Press, 1997.

[11] Ellis, R. Second Language Acquisition Research and Language Teaching. London: Oxford University Press, 1997.

[12] Feez, S. Text-based Syllabus Design. Sydney: National Center for English Teaching and Research, 1998.

[13] Harmer, Jeremy. How to Teach English. Harlow: Longman, 1998.

[14] Harmer, Jeremy. How to Teach English. Beijing: Foreign Language Teaching and Researching Press, 2000.

[15] Hedge, Tricia. Teaching and Learning in the Language Classroom Oxford:Oxford University Press, 2000. 